\begin{tabular}{|c|c|c|c|c|}
\hline \multirow{2}{*}{ Genes } & \multicolumn{4}{|c|}{ Anti-sera } \\
\hline & $R h$ & St & $\boldsymbol{K} J$ & $R h_{1}$ \\
\hline $\begin{array}{l}R h_{1} \\
R h_{2} \\
R h_{j} \\
R h^{\prime} \\
R h^{\prime \prime} \\
r h \\
R h_{y}\end{array}$ & $\begin{array}{l}+ \\
\pm \\
\pm \\
\frac{+}{?}\end{array}$ & $\begin{array}{l}+ \\
+ \\
+ \\
+ \\
+\end{array}$ & 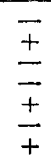 & $\frac{ \pm}{ \pm}$ \\
\hline
\end{tabular}

\section{UNCONSIDERED TRIFLES IN OUR DIET}

\author{
VITAMIN CONTENT OF BEVERAGES
}

\section{By SIR J. C. DRUMMOND and $D_{R}$. T. MORAN}

T will be of interest to students of nutrition to 1 point out some of the important results that have been obtained during the past twelve months from a re-examination of the contribution made to the nutritive value of our diet by common foods that are often ignored when evaluations are being made.

One of us (T. M.), in collaboration with Dr. J. B. Hutchinson', pointed out that water drunk in one form or another can add substantially to the daily calcium intake. An approximate estimate of that provided by drinking-water alone over the country as a whole was $75 \mathrm{mgm}$. a day. In some areas where the water is 'hard', the figure would be much larger. A modest pint of beer daily can provide about $70 \mathrm{mgm}$. . Such quantities should not be ignored in calculating calcium intakes. Widdowson and $\mathrm{McCance}^{2}$ have also stressed the importance of calcium from such sources, and have shown that contact of food with iron utensils often materially raises the quantity of iron in the diet.

Consideration of beer led to a re-investigation of its vitamin content. Since the original study by Harden and Zilva 8,4 , it has been widely assumed that beers consumed in Great Britain have a vitamin content that is negligible. In the Medical Research Council Special Report on Vitamins ${ }^{5}$ published in 1932, there is, however, a reference to an unpublished observation by Aykroyd that stout contains what was then known as "vitamin $\mathrm{B}_{2}$ ", but no further information about this has been traced. In view of the properties of ribofldvin and nicotinic acid, as contrasted with those of $B_{1}$ which is readily adsorbed by yeast, it appeared reasonable to expect that beer would contain a high proportion of the amounts of these two substances contained in the malt. This has proved to be the case. Both in the laboratories of the Cereals Research Station of the Ministry of Food and in Prof. R. H. Hopkins's Department at the University of Birmingham, riboflavin values for beers ranging from 0.5 to $1 \cdot 7 \mu \mathrm{gm}$./c.c. have been found ${ }^{6,7}$

The riboflavin content of beer appears to be related to the strength of the brew. Samples of malt that we have examined have given values of $5 \cdot 6 \mu \mathrm{gm} . / \mathrm{gm}$. (as against $2.5 \mathrm{\mu gm}$./gm. for barley), and on the basis of one pound of barley yielding three and a half pints of beer (corresponding roughly to present-day beer) it would follow that complete extraction of the riboflavin from the malt would give a beer of approximately $1 \cdot 3 \mu \mathrm{gm}$./c.c. Complete extraction is unlikely, but it indicates the limiting riboflavin content. On the other hand, a sample of strong ale as supplied to Queen's College, Oxford, before the War gave a riboflavin figure of $3.9 \mu \mathrm{gm}$./c.c. What promised to be an even more interesting ale-a brew of 1798 to celebrate the battle of the Nile, kindly supplied to us by Mr. Julian Baker-gave the disappointing figure of $0.8 \mu \mathrm{gm} . / \mathrm{c} . c$. Very probably there had been some destruction of the vitamin during the intervening 150 years.

In these examinations the riboflavin values were determined by the microbiological technique ${ }^{8}$, but a biological test on a sample of beer sent to Miss Copping 
of the Lister Institute has given the value of 0.7 $\mathrm{gm}$./gm., or identical with that obtained microbiologically.

Beer is a good source not only of riboflavin but also of nicotinic acid (of the order of $15 \mu \mathrm{gm} . / \mathrm{c.c}$. ), and it is also a reasonable assumption that it contains appre. ciable amounts of other recently identified nutrients, such as biotin, pantothenic acid and inositol. As regards the latter, there is appreciable destruction of phytic acid during germination, with a corresponding increase in the amount of inositol present. Thus in a sample of malted English wheat the phytate phosphorus was found to be $190 \mathrm{mgm}$. per cent as against an average figure of $270 \mathrm{mgm}$. before germination. In passing, we cannot refrain from directing attention to these new aspects of the nutritional merits of that popular lunch-bread, cheese and beer.

Brewed vinegars are also of interest in this connexion, and in the case of riboflavin have been found to have a content of approximately $0.7 \mu \mathrm{gm} . / \mathrm{c} . c$. Artificial vinegars, as would be expected from their composition, contain no nutrient materials.

The riboflavin content of beer seems to provide part of the explanation of the relative rarity in Great Britain of clear-cut symptoms of deficiency conditions. This is in striking contrast to what is seen in the United States and Canada. When Dr. V. P. Sydenstricker, one of the leading authorities on riboflavin and other deficiency conditions, was in England a short time ago, he was greatly impressed by the contrast but he found it difficult to give a plausible explanation. Beer drinking does not provide a com. plete answer, because there is no evidence that abstainers show a high incidence of signs of riboflavin deficiency. When one of us (J.C. D.) was recently in Washington, Dr. W. H. Sebrell informed him that he had obtained evidence of the presence of appreciable amounts of riboflavin in tea. This has been followed up with the following results, obtained on a few samples.

$$
\begin{array}{lcccc} 
& & & & \mu \mathrm{gm} \text {. per gm. } \\
\text { Tea } & \ldots & \ldots & \ldots & 9 \cdot 0 \\
\text { Coffee } & \ldots & \ldots & \ldots & 1 \cdot 7 \\
\text { Cocoa } & . & . & . & 2 \cdot 7
\end{array}
$$

These figures indicate that an amount of the order of $10 \mu \mathrm{gm}$. of riboflavin might be provided by a breakfast cup of tea. The daily quantity would certainly not be negligible in the case of the habitual tea drinker.

Following the same line of reasoning that led to the re-examination of beer, it was thought desirable to analyse commercial meat extracts. For a long time these have been dismissed by nutrition experts as of little or no value as foods. Lean meat is, however, a good source of nicotinic acid and contains an appreciable amount of riboflavin. Consideration of the methods of manufacturing meat extracts suggests that there would be considerable leaching out of these vitamins into the extract. This appears to be the case, since five well-known proprietary brands of meat extract gave riboflavin and nicotinic acid values in the ranges of $15 \cdot 4-25 \cdot 8$ and 410 $1,025 \mu \mathrm{gm} . / \mathrm{gm}$. respectively. A breakfast cup of these extracts would provide on the average $0.2 \mathrm{mgm}$. of riboflavin and $7 \mathrm{mgm}$. nicotinic acid. These quantities are by no means insignificant.

It is possible that the relatively high nicotinic acid content of meat extracts may prove to be related to their reputation as stimulants. The recent work of Frankau is of interest in this connexion.
The experimental results reported above are only preliminary, but they are clearly of importance not only in connexion with an accurate assessment of our overall intake of nutrients but also in indicating fruitful lines of research in malting and food processing generally. It is certain that in brewing research in the future, stress will be laid on the conditions of malting and mashing that will give the maximum production of vitamins consistent with other requirements in the brewing process. Malted cereals would indeed appear to be deserving of the most careful study. Malt. extracts may appear in a now light. Examination of a random concentrated sample gave a value indicating a riboflavin content of $8 \mu \mathrm{gm}$. per gm.; the nicotinic acid content will be correspondingly high. Malt products may, therefore, be of considerable importance as ingredients in bread and such products as breakfast foods, chick foods, otc.

Meat extracts are only half the story of meat processing; any concentration of vitamins in extracts means a corresponding poverty in corned beef. Likewise the inclusion before the completion of the process of any material extracted in the preliminary treatment of meat before drying is desirable not only on grounds of palatability but also of nutritive value.

This communication refers mainly to work being carried out at the Cereals Research Station of the Ministry of Food, St. Albans, particularly by Drs. E. C. Barton-Wright and R. G. Booth. Full details of this work will shortly be published.

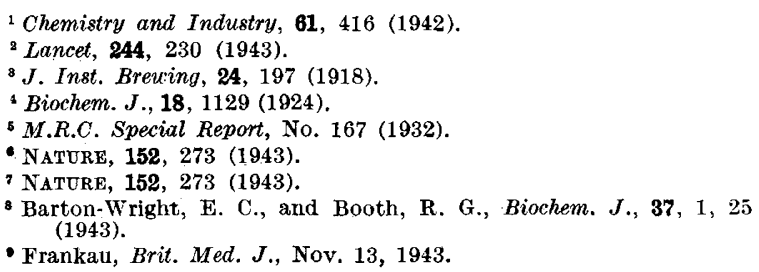

\section{PRESERVATION OF FOODS BY DRYING}

\author{
By $D_{R}$ FRANKLIN KIDD \\ Superintendent, Low Temperature Research Station,
Cambridge
}

RIED foods as a war development have been well advertised, particularly in the United States of America. With the exception of dried egg and dried skim milk ('household milk'), they have not, however, been on sale to the general public in Great Britain. The intelligent layman, therefore, in view of what he has been told through the Press about the exceptionally good quality of dried foods which modern science and technology have been able to achieve, although probably sceptical, would naturally like to try them.

An account appeared in NATURE of August 22, 1942, of a joint meeting of the Nutrition Society and of the Food Group of the Society of Chemical Industry at which the Department of Scientific and Industrial Research demonstrated the results achieved by British science during the War in improving the quality of dried foods. Dried vegetables-potato, cabbage, onions, swede-dried meat, dried egg, dried fish, dried milk and dried soups were served at lunchtime for appraisal by some hundreds of scientific and 